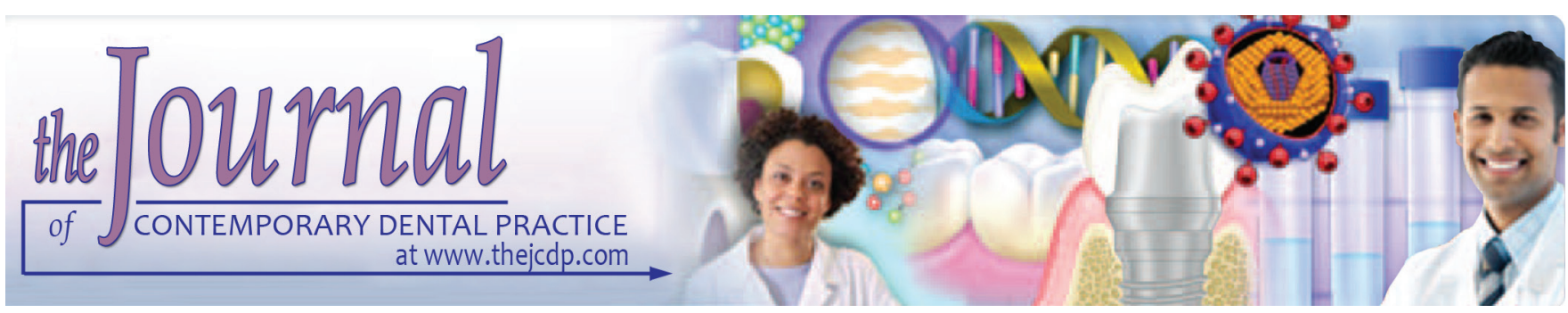

\title{
Pulp Stones, Prevalence and Distribution in an Iranian Population
}

\author{
${ }^{1}$ Maryam Kuzekanani, ${ }^{2}$ Jahangir Haghani, ${ }^{3}$ Laurence J Walsh, ${ }^{4}$ Mohammad AM Estabragh
}

\begin{abstract}
Aim: This study determined the prevalence and distribution of pulp stones in the permanent dentition of an adult population using their periapical radiographs.
\end{abstract}

Materials and methods: The study followed a cross-sectional design. A total of 800 periapical radiographs collected from 412 patients attending dental clinics in Kerman, Islamic Republic of Iran, were examined using magnification.

Results: Pulp stones were present in $9.6 \%$ of all permanent teeth examined, being most common in maxillary first and second molars, followed by mandibular first and second molars. They were present in $31.5 \%$ of all adult patients, with a significantly increased prevalence in females compared with males $(40.5$ vs $23.9 \%$, chi-squared test $p<0.001)$. There was also an increased prevalence with age.

Conclusion: Based on the results of this study, clinicians should expect to encounter pulp stones most commonly in the pulp chambers of maxillary first and second molars, particularly in older female patients.

${ }^{1}$ Department of Endodontics, Endodontology Research Center School of Dentistry, Kerman University of Medical Sciences and Health Services, Kerman, Islamic Republic of Iran; Department of Endodontics, Kerman Dental School, Kerman, Islamic Republic of Iran

${ }^{2}$ Department of Oral and Maxillofacial Radiology, Endodontology Research Center, School of Dentistry, Kerman University of Medical Sciences and Health Services, Kerman, Islamic Republic of Iran; Department of Oral and Maxillofacial Radiology, Kerman Dental School, Kerman, Islamic Republic of Iran

${ }^{3}$ Department of Science and Technology, UQ Oral Health Centre, School of Dentistry, University of Queensland, Herston Queensland, Australia; Dental Sciences School of Dentistry The University of Queensland, Brisbane Queensland, Australia

${ }^{4}$ Endodontology Research Center, School of Dentistry, Kerman University of Medical Sciences and Health Services, Kerman Islamic Republic of Iran

Corresponding Author: Maryam Kuzekanani, Department of Endodontics, Endodontology Research Center, School of Dentistry, Kerman University of Medical Sciences and Health Services, Kerman, Islamic Republic of Iran; Department of Endodontics, Kerman Dental School, Kerman, Islamic Republic of Iran, Phone: +91989131416717, e-mail: maryamk6717@ gmail.com
Clinical significance: Pulp stones depending on their size and location can pose challenges to endodontic treatment. They obstruct access to the canal orifices and thus complicate endodontic treatment. Knowing where and when pulp stones are likely to occur improves the quality of root canal treatments.

Keywords: Calcification, Endodontics, Prevalence, Pulp stones.

How to cite this article: Kuzekanani M, Haghani J, Walsh LJ, Estabragh MAM. Pulp Stones, Prevalence and Distribution in an Iranian Population. J Contemp Dent Pract 2018;19(1):60-65.

Source of support: Nil

Conflict of interest: None

\section{INTRODUCTION}

Pulp stones are calcified deposits present in the dental pulp that appear in radiographs as round or ovoid opacities within the pulp chamber. They are considered to be a physiological manifestation of changes to the pulp tissue, rather than a pathological entity per se. So-called "true" pulp stones are composed of dentin and are lined by odontoblasts, whereas "false" pulp stones are formed when degenerating pulp tissue become mineralized. ${ }^{1}$

The recent studies have shown that pulp stones have heterogeneous structures and chemical compositions. $\mathrm{X}$-ray diffraction has revealed partially carbonated apatite while X-ray fluorescence has identified $\mathrm{P}, \mathrm{Ca}, \mathrm{Cu}, \mathrm{Zn}$, and $\mathrm{Sr}$ within dentin and pulp stones. $\mathrm{Zn}$ and $\mathrm{Cu}$ concentrations are higher in pulp stones and carious dentin compared with healthy dentin. ${ }^{2}$

Pulp stones can occur in any type of tooth, and they tend to increase in number or size over the adult years of the life span. While the precise etiology of pulp stone formation is yet to be described fully, known factors which predispose to their development include traumatic occlusion, caries, restorative interventions, orthodontic treatment, periodontal disease, and aging. ${ }^{3-7}$

Depending on their size and location in the pulp chamber, pulp stones can complicate endodontic treatment by impairing access to the root canal orifice through the physical obstruction. Their presence can lead to 
changes in access cavity preparation in endodontics and slow down the progress of cleaning and shaping the root canal system, particularly for molar teeth. The problems that they cause are similar to those from secondary and tertiary dentin formation. ${ }^{4-7}$

Pulp stones have been reported to be present in patients with systemic or genetic diseases, such as dentin dysplasia and dentinogenesis imperfecta; in certain syndromes, such as Williams and Van der Woude syndromes, in renal diseases, and also in cancer patients with bisphosphonate-induced osteonecrosis. ${ }^{4,8-12}$

The aims of this study were to determine the prevalence and distribution of pulp stones in permanent teeth in an adult population using periapical radiographs and explore possible associations with age, gender, tooth type, and tooth location. It was also of interest to compare prevalence rates for the study population (based in Kerman, Islamic Republic of Iran) to published data from other regions of the world.

\section{Statement of the Problem}

Pulp stones are rigid structures that develop in the coronal or radicular pulp. They obstruct access to the canal orifices and thus complicate endodontic treatment. ${ }^{1,3}$ A range of techniques, both chemical and mechanical, can be used to remove them. Knowing where and when pulp stones are likely to occur should improve the quality of root canal treatments that are undertaken. ${ }^{4}$

\section{MATERIALS AND METHODS}

The study followed a cross-sectional design and was approved by the institutional ethics committee (approval number IR.KMU.REC.1394.385). The patient cohort comprised 412 adult patients (age 15-65 years), with 184 males and 228 females attending community-based clinics for routine dental care in Kerman, Islamic Republic of Iran. A total of 800 periapical radiographs were collected from existing dental records and details of age and gender recorded. No new radiographs were taken for the study. Of the 800 radiographs, 650 were digital, while the remainder were films. Using magnification, all radiographs were scored for the presence of pulp stones. The radiographs were interpreted by one examiner. Films were viewed on a standard viewing box and under subdued ambient light with the aid of a magnifying glass (up to $\times 4$ magnification), while digital images were viewed on the screen under partial darkness. Any radiographs which were taken at the wrong angulation, incorrectly exposed or processed were not used, and were excluded from the total. Pulp stones were scored as being present or absent based on the presence of well-defined radiopaque bodies in the pulp chambers of the teeth. Data for prevalence were assessed using chi-squared test.

\section{RESULTS}

Pulp stones were detected in $31.5 \%$ of the patients $(40.48 \%$ of females and $23.9 \%$ of males) and $9.6 \%$ of all tooth types in the dental arch. They were mainly found in the maxillary and mandibular first, second, and third molars in 412 patients (184 males and 228 females), in this Iranian population. This study showed that pulp stones are found more frequently in old patients than in young ones, and also they are more prevalent in women than men (X-test, $\mathrm{p}<0.001$ ) (Fig. 1).

\section{DISCUSSION}

In this study, the data were collected from the examination of periapical radiographs of patients who attended the School of Dentistry, dental offices, and dental clinics in Kerman.

Observation of pulp stones in this study was based on periapical radiographs, though it is important to note that not all of the calcifications in pulp could be seen on radiographs. The detection of pulp stones on dental radiographs is possible when pulp stones are larger than $200 \mu \mathrm{m}$ in diameter; therefore, very small pulp stones cannot be seen on radiographs. ${ }^{1,4,8,10,13-16}$

The prevalence of pulp stones in the examined teeth of this research was $9.6 \%$. They were found to be more prevalent in the maxillary arch, especially in the first and second molars. Ravanshad et $\mathrm{al}^{17}$ also in a study which was performed on 625 randomly selected bitewing and periapical radiographs of just the mandibular and maxillary molar teeth from patients who attended Shiraz Dental School, Shiraz, Islamic Republic of Iran, reported that from the total of the 652 subjects examined, 306 (46.9\%) had one or more teeth with pulp stones. Of the 8,244 posterior teeth examined, 928 (11.25\%) had pulp stones in the pulp chamber. These pulp stones were detected in 76 (37.6\%) males, and 230 (51\%) females had almost a similar pattern. Among the teeth showing the condition, first molars were the most prevalent, followed by second molars. In maxillary molars, the frequency of occurrence (26\%) was higher than mandibular molars $(18.7 \%)$. The overall rate of the pulp stone incidence that resulted from this recent study in Islamic Republic of Iran cannot be compared with our findings, since Ravanshad et $\mathrm{al}^{17}$ study did not involve all tooth types including anterior teeth and premolars in the dental arch. However, the results of the maximum rate of pulp stone occurrence in maxillary first and second molars and also the higher incidence in women than men are in agreement with our findings.

In a retrospective study on 469 patients' bitewing radiographs (302 females and 167 males) which was done to determine the prevalence of pulp stones in a Turkish population, pulp stones were identified in 270 (57.6\%) 

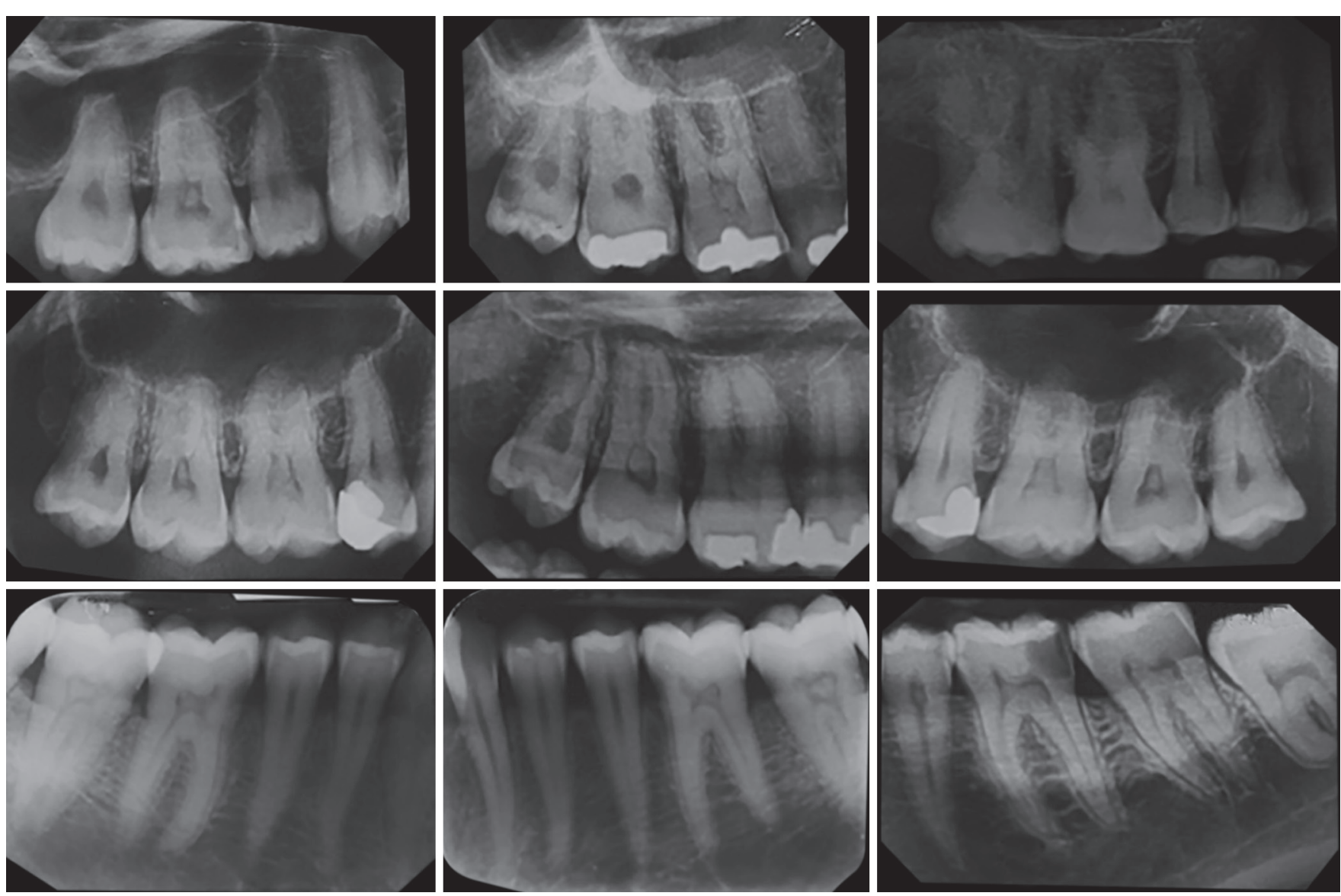

Fig. 1: Intraoral periapical radiograph of the teeth showing pulp stones

of the subjects, and 1,038 (15\%) of the teeth examined. They were seldom found in the premolars $(9.07 \%)$ but were much more prevalent in the molars $(90.92 \%)$. Pulp stone occurrence was significantly more common in the first molars than in the second molars and in the first premolars than in the second premolars in each dental arch. Their occurrence was higher in the maxilla than in the mandible for each tooth type. No difference between the two genders could be identified.

The incidence rate (15\%) in this Turkish population was higher than our study in this population from Islamic Republic of Iran. ${ }^{15}$

Another retrospective study on panoramic radiographs from 6,912 patients attending Kirikkale University Dental Faculty Hospital, Kirikkale, Turkey, over 2009 to 2011 reported pulp stones to happen in 879 out of 6,912 patients $(12.7 \%)$ and also to be viewed in 2009 teeth out of a total of 96,240 teeth, showing a tooth prevalence of $2.1 \%$. According to the findings of that study, the prevalence of pulp stones was higher in the maxilla than in the mandible for each tooth type. Pulp stones were found to involve the right side more than the left side, and they were significantly more common in females than males. ${ }^{18}$

The incidence of pulp stones reported by Baghdady et $\mathrm{al}^{8}$ resulted from radiographic examination of 515 randomly selected Iraqi patients (19.2\%), which is lower than the reported rate (31.5\%) in Kerman, Islamic Republic of Iran. According to Baghdady's findings, pulp stones happened more frequently in males than in females, and also they were found significantly more in mandibular teeth than in the maxillary teeth. First molars exhibited significantly more pulp stones than the second molars and premolar teeth, in both jaws and both genders. A slightly higher percentages of pulp stones were detected in carious teeth than in intact teeth.

Ranjitkar et $\mathrm{al}^{13}$ in a study on bitewing radiographs ( $\times 2$ magnification) related to 217 dental students in Australia that comprised 123 males and 94 females aged between 17 and 35 years found pulp stones in $100(46.1 \%)$ of the subjects and $333(10.1 \%)$ of the teeth examined. Pulp stones happened rare in the premolars $(0.4 \%)$ but significantly higher in molars (19.7\%). Carious and/or restored maxillary right first molars and maxillary left second molars displayed higher prevalences of pulp stones than unrestored and intact molars. The overall prevalence of pulp stones in all tooth types of this Australian group is almost the same as the rate reported in Kerman, Islamic Republic of Iran. Kannan et $\mathrm{al}^{19}$ in a radiographic assessment of the prevalence of pulp stones in 361 patients (205 female and 156 males) in a group of Malaysians identified pulp stones in $162(44.9 \%)$ subjects and 280 (15.7\%) teeth of the total of 1,779 teeth under the study. Pulp 
stones were found significantly more in molars and teeth that were not intact (carious/restored). They found no significant correlation between gender, age, dental arch, and ethnic backgrounds with the prevalence of the pulp stones in a Southeast Asian community.

Bains et $\mathrm{al}^{20}$ in a study which was carried out on the molar bitewing radiographs of the left and right side of 500 dental patients within the age group of 18 to 67 years in Sunam, Sangrur district, Punjab, India, reported an overall prevalence of pulp stones of $41.8 \%$.

Pulp stones were found significantly higher in maxilla (11.59\%) than mandible (6.54\%), left side than right side, women than men, and first molar than other molars. Higher numbers of pulp stones were recorded in patients with cardiovascular disease (CVS; 38.89\%) than with cholelithiasis and renal lithiasis. ${ }^{20}$ Da Silva et $\mathrm{al}^{21}$ in a recent retrospective study on a group of Brazilians which evaluated the occurrence of pulp stones by conebeam computed tomography (CBCT) and the correlation of their prevalence with patient's gender, side of the tooth (right or left of maxillary or mandibular arch), type of teeth, and restorations found that the prevalence of pulp stones was similar between patient's genders and tooth sides. Pulp stones were detected in $31.9 \%$ of patients and $9.5 \%$ of teeth. Maxillary and mandibular molars were the groups of teeth with the highest frequency of pulp stones. The presence of restorations increased the chance of occurrence of pulp stones by 2.1 times in all teeth examined $(\mathrm{p}<0.0001)$ and by 4.7 times in maxillary teeth $(p<0.0001)$. The presence of restorations increased the chance of occurrence of these calcifications, specifically in maxillary teeth. They showed that CBCT provides accurate anatomical details in three dimensions, offering the possibility to view an individual tooth in axial, sagittal, and coronal views. Weber et $\mathrm{al}^{22}$ have also reported that microscopic anatomical structures of the pulp tissue, such as side canals, ramifications, communications, pulp stones, obliterations, and the length of curved root canals could be determined precisely by CBCT as well.

Talla et $\mathrm{al}^{23}$ in a study which assigned the prevalence and distribution of pulp stones in a group of patients from Andhra Pradesh, India, also determined the association of pulp stones with systemic diseases. They reported that the pulp stones occurred in 799 (17.9\%) of 4,449 teeth under the study. They noted significantly higher numbers of pulp stones in patients with systemic diseases, such as CVS disorders, type II diabetes mellitus, and gastritis. Pulp stones occurred significantly higher in maxillary first and second molars. They found no significant difference between genders and sides in this Indian population. Ertas et $\mathrm{al}^{6}$ in a retrospective clinical follow-up study which was done to assess the incidence of dental pulp stone formation during nonextraction orthodontic treatments also determined the correlations between the presence of dental pulp stones and age, gender, and dental arches on a sample of 545 patients (334 females and 211 males, age of 12-22 years) and noted the pulp stones in 3\% of the teeth at pretreatment panoramic radiographs and $5.2 \%$ of the teeth at posttreatment panoramic radiographs in a group of Turkish patients. Pulp stone prevalence increased pointedly $(2.2 \%)$ in the pre- and posttreatment radiographs $(\mathrm{p}<0.001)$.

They found a significant difference between the age groups $(\mathrm{p}<0.001)$. In the maxilla, pulp stones were found significantly more than the mandible. Maxillary first molars exhibited dental pulp stones most frequently, followed by the maxillary second molars and mandibular first molars. They came to this conclusion that orthodontic treatment may trigger the formation of dental pulp stones. ${ }^{6}$

Han et $\mathrm{al}^{24}$ in a study investigated pulp vitality and histologic changes after the application of moderate and severe intrusive forces and noted odontoblast disruption, vacuolization, and moderate vascular congestion in both force groups, but no necrosis was observed. Pulp stones were formed only in the severe force group. Fatemi et $\mathrm{al}^{7}$ in a human study which was performed on the hematoxylin and eosin-stained histologic sections obtained from 20 hopeless permanent teeth, extracted from systemically healthy adults because of moderateto-advanced chronic periodontitis, with a bone loss of $>6 \mathrm{~mm}$ and a mobility of grades II or III, evaluated the possible effects of periodontal disease on the dental pulp. They reported that most teeth (58.3\%) displayed edematous pulps. Slightly fibrotic pulps were seen in $52.1 \%$ of the sections. Odontoblastic integrity was detected in $31.3 \%$ of the samples. Noninflamed pulp, with partial or complete necrosis in some sections and non-necrotic sections, was found in only $6.3 \%$ of teeth. Most teeth (77.1\%) displayed no pulp stones. In $43.8 \%$ of teeth, the pulp vessels displayed dilatation. They concluded that moderate-to-advanced periodontal disease can affect the dental pulp structure, so careful diagnostic and treatment planning in patients with endoperio involvements has to be considered by the clinicians.

Negm et $\mathrm{al}^{25}$ compared the biological properties of a new pulp capping material developed from portland cement with those of the popular similar material, mineral trioxide aggregate (MTA), saw loss of normal architecture, areas of necrosis, complete or incomplete dentin bridge formation, attached and detached pulp stones, and fatty degeneration in the pulp sections which were capped by this material, and on the contrary, they reported normal pulp, continuous odontoblastic layer, and complete dentin bridge formation in the MTA group. Review of the literature clarifies that the dental pulp stones shape as an idiopathic or biologic reaction of the pulp to certain 
irritants, such as caries, restorations, traumatic occlusion, periodontal diseases, orthodontic treatments, and vital pulp regenerations. Some systemic diseases and genetic syndromes may also trigger the occurrence of these subjects that may make orifice findings and access to the root canal a thorough challenge in endodontic treatments. Using the dental surgical operating microscope or microscope-level loupes, magnification of $\times 68$ or greater, combined with head-mounted or coaxial illumination improves the ability of a dentist to identify microscopic root canal orifices and also facilitates to achieve adequate straight-line access in pulp stone cases specially in maxillary molars. Piezoelectric or ultrasonic instruments and also new nickel-titanium rotary instruments are efficient facilities for revealing root canal orifices and removing pulp stones or calcified pulp.,26-29

\section{CONCLUSION}

Pulp stones were detected in $9.6 \%$ of all tooth types in the dental arch and were mainly found in the maxillary and mandibular first, second, and third molars in 412 patients (184 males and 228 females) in the Iranian population. Pulp stones were mostly found in first and second maxillary molars, with first and second mandibular molars being the second most prevalent location. Pulp stones were found to be more prevalent in women than men and happened more in old patients rather than the young ones, according to the findings of this study.

Different studies in different parts of the world suggest an average prevalence of 10 to $20 \%$ for pulp stones in all tooth types, with significantly higher incidence in molars, maxillary arch, females, and aged groups. In some systemic diseases and also genetic syndromes, higher occurrence of these subjects must be considered. The CBCT, dental microscope, magnifying loops, and nickel-titanium rotary instruments are promising facilities to find and bypass these stones and orifice or root canal obstructions.

\section{ACKNOWLEDGMENTS}

Authors would like to thank the staff of the Department of Oral and Maxillofacial Radiology of Kerman Dental School and other dental centers in Kerman for providing the files and radiographies of the patients in this study. Furthermore, special thanks are dedicated to Dr Mirzaei Estabragh on his hard work to achieve his DDs Thesis.

\section{REFERENCES}

1. Neville, BW.; Damm, DD.; Allen, CM.; Chi, AC. Oral and maxillofacial pathology. 4th ed. St Louis (MO): Elsevier; 2016. p. 113-116.
2. Berès $\mathrm{F}$, Isaac J, Mouton L, Rouzière $\mathrm{S}$, Berdal A, Simon $\mathrm{S}$, Dessombz A. Comparative physicochemical analysis of pulp stone and dentin. J Endod 2016 Mar;42(3):432-438.

3. Hargreaves, KM.; Berman, LH. Cohen's pathways of the pulp. 11th ed. St Louis (MO): Mosby; 2016. p. 149.

4. Goga R, Chandler NP, Oginni AO. Pulp stones: a review. Int Endod J 2008 Jun;41(6):457-468.

5. Mamoun JS. The maxillary molar endodontic access opening: a microscope-based approach. Eur J Dent 2016 Jul-Sep;10(3):439-446.

6. Ertas ET, Veli I, Akin M, Ertas H, Atici MY. Dental pulp stone formation during orthodontic treatment: a retrospective clinical follow-up study. Niger J Clin Pract 2017 Jan;20(1):37-42.

7. Fatemi K, Disfani R, Zare R, Moeintaghavi A, Ali SA, Boostani HR. Influence of moderate to severe chronic periodontitis on dental pulp. J Indian Soc Periodontol 2012 Oct-Dec;16(4):558-561.

8. Baghdady VS, Ghose LJ, Nahoom HY. Prevalence of pulp stones in a teenage Iraqi group. J Endod 1988 Jun;14(6): 309-311.

9. Kansu O, Ozbek M, Avcu N, Aslan U, Kansu H, Genctoy G. Can dental pulp calcification serve as a diagnostic marker for carotid artery calcification in patients with renal diseases? Dentomaxillofac Radiol 2009 Dec;38(8):542-545.

10. Wong D, Ramachandra SS, Singh AK. Dental management of patient with Williams Syndrome-a case report. Contemp Clin Dent 2015 Jul-Sep;6(3):418-420.

11. Yeluri G, Kumar CA, Raghav N. Correlation of dental pulp stones, carotid artery and renal calcifications using digital panoramic radiography and ultrasonography. Contemp Clin Dent 2015 Sep;6(Suppl 1):S147-S151.

12. de Camargo Moraes P, Silva CA, Soares AB, Passador-Santos F, Corrêa ME, de Araújo NS, de Araújo VC. Tooth alterations in areas of bisphosphonate-induced osteonecrosis. Clin Oral Investig 2015 Mar;19(2):489-495.

13. Ranjitkar S, Taylor JA, Townsend GC. A radiographic assessment of the prevalence of pulp stones in Australians. Aust Dent J 2002 Mar;47(1):36-40.

14. Arys A, Philippart C, Dourov N. Microradiography and light microscopy of mineralization in the pulp of undemineralized human primary molars. J Oral Pathol Med 1993 Feb;22(2):49-53.

15. Sisman Y, Aktan AM, Tarim-Ertas E, Ciftçi ME, Sekerci AE. The prevalence of pulp stones in a Turkish population. A radiographic survey. Med Oral Patol Oral Cir Bucal 2012 Mar;17(2):e212-e217.

16. Tamse A, Kaffe I, Littner MM, Shani R. Statistical evaluation of radiologic survey of pulp stones. J Endod 1982 Oct;8(10):455-458.

17. Ravanshad S, Khayat S, Freidonpour N. The prevalence of pulp stones in adult patients of Shiraz Dental School, a Radiographic Assessment. J Dent (Shiraz) 2015 Dec;16(4):356-361.

18. Turkal M, Tan E, Uzgur R, Hamidi M, Colak H, Uzgur Z. Incidence and distribution of pulp stones found in radiographic dental examination of adult Turkish dental patients. Ann Med Health Sci Res 2013 Oct-Dec;3(4):572-576.

19. Kannan S, Kannepady SK, Muthu K, Jeevan MB, Thapasum A. Radiographic assessment of the prevalence of pulp stones in Malaysians. J Endod 2015 Mar;41(3):333-337.

20. Bains SK, Bhatia A, Singh HP, Biswal SS, Kanth S, Nalla S. Prevalence of coronal pulp stones and its relation with 
systemic disorders in northern Indian central punjabi population. ISRN Dent 2014 Apr;22:75-79.

21. Da Silva EJ, Prado MC, Queiroz PM, Nejaim Y, Brasil DM, Groppo FC, Haiter-Neto F. Assessing pulp stones by cone beam computed tomography. Clin Oral Investig 2016 Dec;21(7): 2327-2333.

22. Weber MT, Stratz N, Fleiner J, Schulze D, Hannig C. Possibilities and limits of imaging endodontic structures with CBCT. Swiss Dent J 2015 Jul;125(3):293-311.

23. TallaHV,KommineniNK, YalamancheliS,AvulaJS, ChillakuruD. A study on pulp stones in a group of the population in Andhra Pradesh, India: an institutional study. J Conserv Dent 2014 Mar;17(2):111-114.

24. Han G, Hu M, Zhang Y, Jiang H. Pulp vitality and histologic changes in human dental pulp after the application of moderate and severe intrusive orthodontic forces. Am J Orthod Dentofacial Orthop 2013 Oct;144(4):518-522.
25. Negm AM, Hassanien EE, Abu-Seida AM, Nagy MM. Biological evaluation of a new pulp capping material developed from Portland cement. Exp Toxicol Pathol 2017 Mar;69(3): 115-122.

26. Ertas ET, Inci M, Demirtas A, Ertas H, Yengil E, Sisman Y, Gokce C. A radiographic correlation between renal and pulp stones. West Indian Med J 2014 Jul 63(6):620-625.

27. Sahoo SR, Aggarwal S. Dentin dysplasia Type 1d: a rare case. Indian J Dent Res 2014 Nov-Dec;25(6):832-834.

28. Kaswan S, Patil S, Maheshwari S, Rahman F, Khandelwal S. The relationship between pulp calcifications and salivary gland calcifications. J Clin Exp Dent 2014 Dec;6(5): e474-e478.

29. Kuzekanani M, Walsh LJ, Yousefi MA. Cleaning and shaping curved root canals: Mtwo versus ProTaper instruments, a lab comparison. Indian J Dent Res 2009 Jul-Dec;20(3): 268-270. 